\title{
Europa y América Latina en la crisis financiera mundial: ¿quién puede aprender qué de quién?
}

\section{Europe and Latin America in the global financial crisis: Who learns what from whom?}

doi: http://dx.doi.org/10.32870/espiral.v24i69.5211

Klaus Bodemer*

\begin{abstract}
Resumen
El presente trabajo compara los impactos producidos por la crisis económicofinanciera desde 2008 sobre dos regiones: la Unión Europea y América Latina. Se extraen algunas enseñanzas sobre la base de la evaluación comparativa de esos impactos, y se hacen una serie de recomendaciones orientadas a dificultar que una crisis de este tipo se repita en el futuro o, en caso de que se produjera, destinadas a propiciar un mejor manejo de la misma. Desde el punto de vista teórico, se utilizan planteamientos del neorrealismo, de la perspectiva neoinstitucionalista, del (social)constructivismo (normas, valores, autopercepción, discurso) y del concepto de "two level game" que tematiza el relacionamiento estrecho entre factores internos y externos.
\end{abstract}

Palabras clave: crisis financiera global, crisis de la integración europea, estrategia anticrisis, regulación global, populismo.

\begin{abstract}
The subject of the following paper is to compare the impacts of the financial and economic crisis of 2008 and the following years to the European Union and Latin America. Afier a brief description of the origins and characteristics of the 2008 crisis, the article analyse its effects on the two regions, the implemented politics on both sides and its results. Based on the comparative evaluation of these answers, we deduce some lessons and formulate some recommendations which could contribute to reduce the probability that such crisis repeat in the future or make it at least easier to manage. From a theoretical point of view, we refer to the concepts of neo-realism, new-institutionalism, social-constructivism (norms, values, self-perception, discourse) and, taking on consideration the strong relationship between internal and external factors, "two level game".
\end{abstract}

Keywords: global financial crisis, crisis of the European integration, anti-crisis strategy, global regulation, populism.

\footnotetext{
- Profesor asociado del GIGA Institute of Latin American Studies, Hamburgo, Alemania. klaus.bodemer@giga-hamburg.de

Fecha de recepción: 02 de marzo de 2016. Fecha de aceptación: I4 de febrero de 2017.
} 


\section{La erupción de la crisis financiera internacional (2008-2009). ¿Qué tipo de crisis?}

Lo primero que viene a la memoria asociado al tema de la crisis financiera es América Latina, donde, por ejemplo, en 1982 la crisis de la deuda dio inicio en México a la llamada "década perdida". La crisis en la región era entonces el efecto tardío del reciclaje de los petrodólares en los años 70, y fue causada por el aumento espectacular de los tipos de interés, decidido por Paul Volcker, presidente de la Reserva Federal de los EE.UU. La decisión de Volcker provocaría no sólo una recesión en EE.UU. y en Europa, sino también la llamada "crisis de la deuda "en el tercer mundo, sobre todo en América Latina y el Caribe. Esa crisis desencadenó la fuga de capitales, el rescate de los bancos por parte de los Gobiernos, la conversión de los Gobiernos, la conversión de las deudas privadas en deudas públicas y la aplicación de programas neoliberales de ajuste.

La crisis tratada en este trabajo, nacida en 2007 en EE.UU. como subprime-crisis o crisis inmobiliaria, alcanzó su primer pico en septiembre de 2008 con la quiebra del big bank de Lehmann Brothers, afectó pronto la economía real y condujo a quiebras de empresas y de bancos y al aumento de las deudas públicas en los países miembros de la Organización para la Cooperación y el Desarrollo Económico (OCDE), primero en EE.UU., después en Europa y Japón, y finalmente, desde el último cuarto de 2008, en el mundo entero. Las bolsas de valores experimentaron caídas dramáticas y los mercados de materias primas registraron un significativo descenso de sus precios en los últimos meses de 2008. En octubre de 2009, la crisis de la banca se transformó en una crisis de deudas estatales provocada por el desastre financiero de Grecia y su consecuente pedido de ayuda al FMI y a la Unión Europea que buscaba evitar una

\section{6}


insolvencia estatal capaz de desencadenar una reacción en cadena dentro de la zona euro.

A pesar de la variedad de explicaciones sobre la crisis desencadenada en 2008, existe un amplio consenso según el cual esta crisis fue, en gran medida, el resultado de un fracaso de la regulación global. El consenso es nuevo, dado que, hasta el estallido de la "burbuja financiera" en el sector inmobiliario en septiembre de 2008, prevalecía, también entre la mayoría de los economistas, la creencia en un crecimiento duradero, así como cierta incapacidad para advertir los "nubarrones" en el horizonte. Ese optimismo incondicional se desplomó cuando Wall Street colapsó. El estado de ánimo cambió dramáticamente en los meses siguientes, cuando la crisis financiera derivó a una crisis de la economía mundial y a una recesión. Desde entonces, algunos observadores se refieren a esta como la peor crisis económica de los últimos ochenta años, un "terremoto devastador", comparable a un tsunami.

Como consecuencia de la crisis, que se extendía mucho más allá del sector financiero, el rol del Estado como actor y gestor de la misma fue cada vez más importante, dado que se sintió obligado a ayudar con sumas gigantescas a la salvación de los bancos y a la de aquellas empresas que por su tamaño y cantidad de empleados habían sido declaradas de "interés nacional". Esto hizo prevalecer un manejo ad hoc de la crisis (crisis management), por encima de consideraciones de una política de ordenamiento. Las medidas de rescate, por su parte, corrieron el riesgo de premiar la mala gestión de algunas empresas con la dotación de suficiente cantidad de empleados, y de alimentar una mentalidad de consumo también en el área del management. El Estado, años antes condenado como responsable de todo lo que funcionaba mal en la economía, según el marco tutelar del llamado "consenso de Washington", se convertía ahora en 
un actor altamente reverenciado, de cuyo papel de salvador siempre disponible se podía incluso abusar.

\section{2. ¿Cómo afectó la crisis financiera a América Latina?}

Las economías latinoamericanas se vieron afectadas tendencialmente por la crisis según su grado de integración en el mercado mundial y su interconexión con los mercados financieros internacionales, o su grado de dependencia de los EE.UU. (Sangmeister, 2010). Entre los países más afectados se hallan, en primer lugar, los de América del Sur. Sus economías, en gran parte centradas en la explotación de materias primas, sufrieron las consecuencias de la reducción de la demanda en el mercado mundial causada por la recesión u otros factores. Esa reducción de la demanda fue además sensible desde el punto de vista político, dado que los Gobiernos, en gran parte de vertiente socialdemócrata, con frecuencia utilizaban los ingresos de las exportaciones para financiar amplios programas sociales con el fin de asegurarse el apoyo político de las capas más desfavorecidas de la población, principales perjudicadas por los programas de ajuste de los años 90 .

Los aumentos de sueldo para trabajadores y empleados del sector formal, negociados por los sindicatos durante los cinco años del boom económico (2003-2008), así como las pensiones de las clases pasivas, toparon en los años siguientes contra una valla infranqueable a consecuencia de la reducción de los ingresos estatales, en concreto a consecuencia del descenso de los precios internacionales de recursos naturales como el petróleo, el cobre y la soja. Simultáneamente, las inversiones extranjeras se redujeron debido a una mayor dificultad para acceder a los créditos; cuando disminuyen los ingresos, aumenta la presión sobre el Estado para que implemente medidas de ayuda a la población. 
Mientras al comienzo la crisis afectó solamente a las economías latinoamericanas con un grado mayor de integración a la economía mundial (por ejemplo, México) y a los mercados financieros internacionales, el impacto llegó más tarde también a los países exportadores de materias primas. Tal fue el caso de Argentina, Brasil (a pesar de su base industrial comparativamente respetable), Bolivia, Perú y Colombia. Los países andinos, los centroamericanos y los del Caribe pudieron, por un lado, y en tanto importadores de recursos naturales, beneficiarse del descenso de los precios de esas materias primas en el mercado mundial, mientras que por otro lado se vieron obligados a corregir hacia abajo sus pronósticos de crecimiento, esto último debido a su cercanía o su interconexión con el espacio del Tratado de Libre Comercio de América del Norte (NAFTA, por sus siglas en inglés) y a la disminución de las remesas provenientes de los EE.UU.

Entonces, el PIB de la región en su conjunto se redujo en 2008-2009 en un 2.3\%. La desocupación en las ciudades, por su parte, creció en un 0.6\%, según datos de la CEPAL y la OIT (CEPAL, OIT, 2009). En el mismo sentido, el ingreso real per cápita se redujo en 2009 en aproximadamente 3\%, las exportaciones de manufacturas fueron un quinto menos que en el año anterior, el ingreso de inversiones extranjeras disminuyó en un 30\% y la deuda externa agregada registró en 2009 un aumento de USD 23.3 mil millones (CEPAL, 2009a). De este modo, llegaba a su fin un "ciclo positivo" de cinco años. Fueron las capas más desprotegidas de la población quienes debieron padecer los impactos sociales negativos, como el aumento del precio de la energía y los alimentos, así como un mercado de trabajo más restringido.

En general, se puede decir que principalmente fueron cinco los canales por los cuales los países latinoamericanos sufrieron el impacto de la crisis: el contagio financiero se dio a través de 1) los créditos externos, 2) las inversiones 
extranjeras, 3) la demanda externa, 4) las remesas y 5) las variaciones de los precios en el sector de las materias primas. Algunos países importadores de materias primas obtuvieron beneficios a corto plazo de sus contratos anteriores con fecha fija (e incluso de sus substitutos, como las inversiones chinas en infraestructura), en contraparte con sus contratos de abastecimiento a largo plazo.

Los países pudieron limitar de ese modo la drástica disminución de divisas. Aquellos dependientes del ingreso de remesas, como los del istmo centroamericano, fueron afectados más rápidamente, dado que sus trabajadores emigrados a los países en crisis fueron los primeros en perder sus empleos al comenzar la recesión. Ambos efectos, tanto la caída de los precios de las materias primas como la reducción de las remesas, generaron devaluaciones, encarecieron el servicio de la deuda externa y amenazaron la estabilidad política interna. Esto redujo considerablemente la capacidad de acción de los Gobiernos nacionales. Además, el difícil acceso al apoyo externo dificultó o incluso hizo inviable la cooperación internacional, lo cual amenazó con restringir la capacidad de gestión de los Gobiernos y con socavar la estabilidad política y la paz social de los países (Langhammer, 2009).

A pesar de los riesgos mencionados, se puede decir que América Latina se mostró mucho más armada para enfrentar las consecuencias negativas de la crisis financiera y económica de 2008-2009 que en situaciones comparables del pasado, lo cual se debió, en algunos casos, a una serie de reformas emprendidas previamente. Los precios en alza de algunas materias primas en la primera década del siglo XXI propiciaron que los países exportadores de estos productos acumulasen un stock respetable de divisas y pusieran en orden sus presupuestos.

Además, la mayor parte de los países latinoamericanos implementó durante estos años una sólida política econó- 
mica. La situación fiscal, la deuda externa, los sistemas financieros y la flexibilidad de la política monetaria y cambiaria funcionaron mejor que en periodos anteriores. Si bien la vulnerabilidad de las actividades en países de despegue, como Brasil y Argentina, constituyó un decisivo factor de riesgo (Mai, 2009), la región se benefició de un sólido sector financiero. Es así que los bancos españoles Santander y BBVA, por ejemplo, ambos muy activos en la región, pudieron contrarrestar las turbulencias en su país de origen gracias a sus fuertes compromisos en América Latina. Ello cambiaría, sin embargo, al desatarse en 2011 la segunda crisis financiera.

También las cifras económicas reflejan el hecho de que América Latina no se vio demasiado afectada por la crisis 2008-2009. La diferencia entre la reducción del PIB en la región y en el mundo fue en el año de crisis 2009 sólo del $0.1 \%$, considerablemente inferior a la registrada en tres recesiones anteriores (1980-1983, el 0.7\%; 1998-1999, el 1.3\%; 2001-2003, el 0.9\%) (Eidelmann, 2010).

La región ha sabido resistir, además, la tentación de restringir el libre comercio con medidas proteccionistas. Algunos países de la región decidieron más bien intensificarlo, para lo cual redujeron las tarifas aduaneras para importaciones de bienes de capital, productos intermedios y alimentos. Otros países redujeron los impuestos de exportación para un conjunto determinado de productos, particularmente los del sector agrario, apoyaron el financiamiento de las exportaciones o tomaron, en conjunto con otros países, las medidas necesarias para financiar las exportaciones con el objetivo de compensar en parte el difícil acceso a créditos causado por la crisis financiera (CEPAL, 2009b). 


\section{3. ¿Cuáles fueron las estrategias anticrisis} en América Latina?

Los Gobiernos de la región reaccionaron al estallido de la crisis financiera a nivel operativo con estrategias anticíclicas muy diversas. Los datos de la CEPAL permiten identificar en general dos corrientes: por un lado, aquellos que apuntaron a la reconstitución de la confianza y al funcionamiento de los mercados financieros; por otro, aquellos cuyo objetivo fue fortalecer la demanda debilitada (CEPAL, 2009b, p. 3). El espectro de las medidas concretas fue en general muy amplio, no sólo por la variedad de los impactos de la crisis en los diferentes países, sino porque los países afectados disponían de un extenso catálogo de recursos y capacidades para enfrentarla.

El objetivo prioritario de los Gobiernos latinoamericanos después de septiembre de 2008 fue asegurar la liquidez y mantener los intereses al nivel más bajo posible, a fin de no estrangular el crecimiento. Por otro lado, el incremento de la liquidez no garantizó automáticamente una mayor oferta de créditos ni una mayor demanda de bienes. Si bien la política monetaria y la cambiaria deben ser parte de un paquete de medidas ordenadas y coherentes, son las medidas de política fiscal las que prometen los mayores efectos (CEPAL, 2009a, p. 3). Sin embargo, también en este caso es necesario diferenciar, dado que las políticas fiscales no siempre producen los efectos esperados. Aquellas medidas que apuntan a incrementar los gastos suelen ser consideradas en un primer momento más eficaces que aquellas que apuntan a reducir los impuestos. Las primeras implican un incremento directo de la demanda, mientras las segundas implican un incremento de los ingresos privados. No obstante, en periodos de crisis e inseguridad, ese aumento de los ingresos privados puede generar un aumento de la cuota de ahorro, más que del consumo. 
También en el caso de priorizar la otra opción, la de incremento del gasto estatal, podrán seguirse diferentes estrategias parciales. Las transferencias directas ofrecen la ventaja de poder ser concentradas en aquellos sectores en los que un aumento del consumo es previsible, si bien presentan mayores dificultades de implementación y también institucionalmente resultan más exigentes que aquellas transferencias carentes de un foco en sectores específicos. Si los gastos estatales se concentran en inversiones en el área de la infraestructura, debe tenerse en cuenta que no todas las inversiones en infraestructura tienen la misma capacidad de generar puestos de trabajo o de fomentar la demanda de bienes de producción local. Además, muchas veces se carece de proyectos ejecutables en el corto plazo. De este modo se explica que con frecuencia los Gobiernos elijan la primera variante de estrategias, por lo menos en el corto plazo, y ello a pesar de la mayor eficacia de la segunda variante, la de estrategias que reducen la cuota de impuestos (o de subvenciones no-focalizadas).

Más allá de la diferenciación ya esbozada en la selección de estrategias, es posible advertir, con respecto a la amplitud de las políticas anunciadas o implementadas, una diferencia importante entre los países de la OCDE y aquellos del sur, y dentro de este último grupo, entre los países de América del Sur, los de América Central y el Caribe, y México, un caso especial, geográficamente parte de América del Norte. Ello obedece al diverso margen de capacidad de implementación de políticas anticíclicas, así como también al grado diferente de instituciones sólidas que implementan las políticas correspondientes. 
4. 20 I I en adelante: la segunda ola de la crisis y la reacción de los países emergentes en América Latina

América Latina ha reaccionado también con una serie de medidas anticíclicas a la segunda ola de la crisis, centrada principalmente en Europa y devenida en una crisis del euro o, incluso, de la integración europea. A partir de la segunda mitad del año 2009, las economías latinoamericanas comenzaron a recuperarse y resurgió un cierto optimismo, reflejado por ejemplo en las declaraciones de la sexta cumbre del G20, en Cannes, en noviembre de 2011. Allí se concedió que la crisis en los EE.UU. y Europa podría debilitar el crecimiento, pero de ningún modo ponerlo esencialmente en peligro. Los pronósticos del FMI confirmaron ese optimismo (FMI, 2012).

Este crecimiento tenía su base, sin embargo, no en el Norte, sino en mercados alternativos en el marco de la creciente cooperación Sur-Sur, y su polo geográfico estaba localizado en el Pacífico. Se trataba de un fenómeno novedoso, que llevó a Sebastián Piñera, entonces presidente de Chile, a sostener que "el siglo XXI es el siglo de América Latina y del Caribe”, y Felipe Calderón, presidente de México, refirió al fenómeno con mayor modestia y habló de "la década latinoamericana" (Núñez, 2011). Los jefes de Estado reunidos en Cannes mencionaron en este contexto una vez más las grandes reservas de divisas que habían reunido muchas economías latinoamericanas, sus sistemas bancarios robustos y también una serie de medidas anticíclicas previstas para el caso de una agudización de la crisis. Por ejemplo, Chile preveía medidas para garantizar los puestos de trabajo e inversiones públicas y privadas, mientras que Brasil preveía reducir los impuestos y los intereses e incentivar el consumo y las inversiones. Por su parte, la presidenta de Argentina, Cristina Fernández, preveía reducir los subsidios para el consumo energético, si bien se abstuvo de explicar cómo 
ello sería factible sin afectar el gusto de los argentinos por el consumo (Núñez, 2011).

Con respecto al juicio sobre la crisis en Europa, los tres presidentes latinoamericanos del G20 (los de México, Brasil y Argentina) hallaron en el socialista François Hollande, vencedor en las elecciones presidenciales de Francia que se celebrarían pocos meses después, un aliado en su crítica a la política de austeridad proclamada por Angela Merkel, así como en su estrategia para desarrollar una política de crecimiento y competitividad. Por su parte, Hugo Chávez, presidente de la República Bolivariana de Venezuela, interpretó que la victoria electoral de Hollande ratificaba los aciertos de su crítica al radicalismo de mercado y de su política expansiva de gastos (Núñez, 2012a).

La nueva agudización de la crisis del euro llevó a que a mediados del año 2012 se oyeran en la arena política y los medios de comunicación latinoamericanos un conjunto creciente de voces exhortando a moderar el optimismo hasta entonces vigente dado el macroclima mundial del momento, claramente deteriorado por la crisis financiera y económica en Grecia, España e Italia (Núñez, 2012b). El peligro de contagio para América Latina radicaba particularmente en el ámbito crediticio. Se volvía realmente más que cuestionable la capacidad de las recientes políticas anticíclicas implementadas en América Latina para atacar con éxito la crisis en caso de que se agotaran las fuentes de financiamiento.

\section{Balance y perspectivas.}

América Latina frente al fin de un ciclo

De la crisis misma y de la manera en que han reaccionado los Gobiernos latinoamericanos, es posible extraer una serie de lecciones y delinear algunas recomendaciones: 
1. Las economías latinoamericanas comprendieron que la raíz del problema de la deuda soberana no estaba única y exclusivamente en la falta de solidez económica de los Estados latinoamericanos, sino que en paralelo había que solucionar las dificultades derivadas de la falta de liquidez (Piñón Antillón, 2014, p. 55).

2. La crisis ha enseñado a los Gobiernos de la región cuán importante es un manejo macroeconómico prudente, más concretamente, una política anticíclica, a fin de poder enfrentar la crisis. Sin embargo, la crisis ha demostrado claramente que el manejo prudente de la macroeconomía por sí solo no es suficiente, pues no llega a inmunizar al país contra la crisis.

3. La crisis ha puesto en evidencia, además, que los países de la región se hallan muy atrás en cuanto a la competitividad. Como revelan los datos del Índice de Competitividad Global del Foro Económico Mundial, para los años 2013 y 2014 las economías de América del Sur, exceptuando la de Chile, han ido perdiendo competitividad internacional una vez pasado el boom de las exportaciones de commodities experimentado por el subcontinente en el periodo 2003-2012. Para alcanzar mejores niveles de productividad, las economías latinoamericanas deben mejorar sustancialmente el funcionamiento de sus instituciones, luchar firmemente contra la corrupción y mejorar la calidad de sus infraestructuras física y humana, áreas en las cuales la región se halla francamente atrasada en comparación con los países de Asia y de Europa Oriental (Oppenheimer, 2010).

También son necesarias las condiciones siguientes para una agenda postcrisis:

1. Un crecimiento balanceado y fundado en una demanda interna y externa y exportaciones mejor diferenciadas para diferentes productos y mercados, a fin de disminuir 
la vulnerabilidad frente a shocks externos (Foxley, 2009, pp. vii y 10-12).

2. Un presupuesto equilibrado y un sector bancario y financiero regulado. Las reformas deberían ser focalizadas.

3. Un acceso más amplio a la formación laboral y al entrenamiento on the job, siguiendo al modelo europeo: una flexibilización del mercado laboral, acompañada por un sistema de protección social, una política industrial y tecnológica activa y, no en última instancia, un aumento de la cuota de mujeres en el mercado laboral (Bensusán, 2006; Foxley, 2009).

Independientemente de los diferentes acentos nacionales, los países latinoamericanos compartieron, respecto a la crisis financiera internacional, la convicción de que el culpable debía buscarse en el Norte y también de que ese Norte podía ahora aprender de las experiencias del Sur. $\mathrm{O}$ sea, que los roles tradicionales se habían invertido y era ahora el Sur quien dirigía al Norte aquellas recetas y recomendaciones recibidas del Norte durante la "década perdida", en que se le exhortaba a poner la casa en orden (Ferrer, 1984). El Sur dirige ese mensaje ahora al Norte con cierta satisfacción, por el hecho de que sean hoy los países del Norte los que están en problemas. Según las palabras del presidente ecuatoriano Rafael Correa, las lecciones que América Latina puede impartir a Europa provienen de que "sufrimos una larga crisis de deuda interna y ahora Europa repite los mismos errores" (La Jornada, 2013, p. 29).

La crisis ha enseñado también la necesidad de prever soluciones en paquete, con una distribución justa de costos, y no soluciones parciales, como por ejemplo reducciones en el presupuesto y austeridad. Esta sería la gran lección a extraer de las crisis latinoamericanas de las últimas décadas (Núñez, 2011). 
De las experiencias latinoamericanas de los años 80 se puede aprender:

1. Que para vencer la crisis de la deuda se requiere aproximadamente una década, y que las políticas anticíclicas deben ir acompañadas de reformas estructurales, dado que el núcleo de la crisis fue entonces estructural, como el de la actual crisis europea. Lo único que se alcanza con políticas anticíclicas es desplazar las reformas necesarias en respuesta al atraso en productividad y competitividad.

2. Mirando hacia el futuro, se puede apreciar de manera diferenciada la vulnerabilidad latinoamericana y también prever un manejo acorde de la crisis. En términos generales, puede afirmarse que el subcontinente ha sobrevivido las dos crisis financieras internacionales sin lesiones sustanciales, y eso a pesar del hecho de que la región dispone de diferentes variantes del capitalismo (Bizberg, 2014). Ello no es poca cosa. América del Sur sufrió más que los países de América Central y del Caribe los efectos de la crisis internacional, pero, gracias a una riqueza de recursos de la que estos carecen, también logró salir de la crisis con mayor éxito.

Sin embargo, desde 2013 el entorno económico internacional está plagado de incertidumbres, y hay indicios de un "fin de la fiesta” de los países emergentes, cada vez más preocupados por el desplome de sus monedas y la fuga de capitales. Las causas de esta súbita mudanza en las expectativas deben buscarse, por un lado, en el anunciado cambio de signo de la política monetaria estadounidense, y por otro, en las políticas de austeridad en la zona euro.

Respecto a lo primero, el Fed (Sistema de Reserva Federal) ha comenzado a retirar desde 2015 los estímulos monetarios, lo que incrementará los intereses y hará que los capitales vuelen hacia los activos estadounidenses. En 
cuanto a lo segundo, dado que la austeridad en los países de la zona euro generó una caída de la demanda interna que a su vez condujo, junto con la devaluación de facto del euro, a importantes superávits comerciales, algunas economías emergentes han pasado a tener un déficit por cuenta corriente. Ello las hace mucho más vulnerables ante lo que economistas llaman “sudden stops”, o reversiones súbitas de los flujos de capital.

Nos encontramos actualmente, por lo tanto, ante un punto de inflexión que lleva a una situación de menor liquidez global, menor crecimiento del comercio internacional y menores precios de las commodities, lo que puede provocar grandes vulnerabilidades en algunos países de la región por tres causas: primero, porque sólo unos pocos han utilizado los ingresos extraordinarios de los "años dorados" para aumentar su tasa de ahorro e inversión, o para diversificar y modernizar sus economías, lo que aumenta su debilidad ante shocks externos y, muy especialmente, ante caídas de los ingresos fiscales; segundo, porque la mayoría de los países de la región son, conjuntamente con Rusia y los países africanos, los únicos que se mantuvieron fuera de las nuevas cadenas de suministro globales, tales como los nuevos megaacuerdos comerciales en marcha (con Estados Unidos, por ejemplo, la Asociación Transatlántica para el Comercio y la Inversión, o TTIP, o el Acuerdo Transpacífico de Cooperación Económica, o TPP). Ello reduce considerablemente su margen de maniobra para contrarrestar con ganancias comerciales una posible caída del crecimiento. Por último, tercero, porque todos los países latinoamericanos han utilizado adecuadamente a lo largo de los últimos seis años el margen de maniobra fiscal y monetario disponible para adoptar políticas anticíclicas y amortiguar el impacto de la gran recesión, pero el margen del que hoy disponen es muy escaso (Steinberg, 2013). En palabras del economista jefe del BID, José Juan Ruiz: "la fiesta ha ter- 
minado y los vientos a favor se han convertido en vientos en contra" (Infolatam, 2014).

\section{Europa y la crisis financiera internacional}

La crisis económico-financiera europea de 2008 en adelante ha sido, en los últimos años, la más visible y más ampliamente discutida de una serie de crisis. Para comprenderla, vale recordar que el derrumbe de 2008 no se produjo de la noche a la mañana, sino que sus orígenes datan de tiempo atrás. Si bien el estallido de la crisis financiera internacional en octubre de 2008 sorprendió a muchos, algunos analistas del comportamiento financiero a nivel global sospechaban desde hace tiempo que tarde o temprano sucedería algo grave, dados los movimientos caóticos en el mercado bursátil.

En la zona euro, ya desde 2004 la mayor parte de las economías había dejado de cumplir los criterios exigidos por el Pacto de Estabilidad y Crecimiento (PEC) y presentaban serias vulnerabilidades. Cuando la crisis bursátil estadounidense se extendió a la zona euro, la desconfianza se centró en las economías más débiles, es decir, en aquellos países cuyo conjunto ha sido denominado con desdén "los PIIGS “ (Portugal, Irlanda, Grecia y España, a los que se sumó poco después Italia). En estos países, los sueldos habían crecido más que la productividad, lo que determinó una revaluación real, así como crecientes déficits en la balanza de pagos. Sin embargo, ya no era posible, como en los tiempos del sistema monetario europeo, corregir esa pérdida de competitividad a través de una devaluación. Con los déficits de la balanza de pagos, se incrementó también el monto de la deuda externa. Pertenecer a la zona euro había posibilitado a estos países de Europa meridional un acceso más fácil a los créditos. Sin embargo, ese capital fue utilizado en gran parte para el consumo y para generosos aumentos de sueldos y pensiones, y

\section{0}


no en inversiones productivas. El resultado es una creciente brecha de desarrollo, tanto dentro de la Unión Europea y sus países miembros como entre el norte y el sur de Europa, lo que circunscribe un conflicto entre los principios-objetivos de la competitividad (según el Tratado de Lisboa) propagados por los países más consolidados de la Unión, y aquellos de la solidaridad consagrados en los tratados constitutivos y reclamados por los países sobreendeudados, en su mayoría de Europa meridional.

El caso ejemplar reciente es la complicada relación entre la Unión Europea y Grecia. Las repercusiones internas son graves, e incluyen tanto un retroceso en el crecimiento, altas cuotas de desocupación y débiles finanzas estatales, como también el peligro de la desintegración de la Unión por el exit de Gran Bretaña (bautizado "brexit"). A ello se suman ataques abiertos en Hungría y Polonia contra el Estado de derecho, núcleo central de la Unión en tanto comunidad de valores, y la actual crisis migratoria. Como consecuencia, se advierte una creciente pérdida de cohesión de la UE. Algunos Estados miembros han comenzado a cerrar sus fronteras, una contravención al Acuerdo de Schengen, que garantiza la libre circulación transfronteriza en veinte países miembros con 400 millones de ciudadanos. Finalmente, vale mencionar la falta de responsabilidad del lado de los acreedores, por ejemplo, de los bancos privados que en muchos casos no analizaron suficientemente la salud económica y financiera de sus clientes.

A los desafíos internos se agregan otros, venidos de fuera: el conflicto con Rusia por la anexión de Crimea, la guerra no declarada en Ucrania y el apoyo del Kremlin al régimen de Assad en Siria constituyen situaciones tan críticas como el terror del Estado Islámico (ISIS, por sus siglas en inglés), tanto en Oriente Medio como en sus ataques suicidas dentro de la UE. 
Particularmente peligroso para el proyecto europeo es, finalmente, el hecho de que cada vez más ciudadanos europeos le retiren su confianza al dejar de creer que la unificación europea resulte útil para brindarles seguridad, bienestar y, en general, una vida mejor. Son muchos, particularmente en Europa meridional, los europeos que se ven a sí mismos como perdedores. Varias encuestas muestran entre 2004 y 2015 un importante descenso de la confianza en la UE. Cada vez más ciudadanos se orientan a las fuerzas políticas de derecha que promueven el cierre de las fronteras, un retorno a posturas nacionalistas y una visión xenófoba. El partido de derecha Front National obtuvo el $27 \%$ de los votos en las últimas elecciones regionales de Francia; en Polonia, por su parte, el partido de derecha PIS ("Ley y Justicia") resultó vencedor en las elecciones, lo cual arroja consecuencias inmediatas para la democracia polaca; en Hungría, el Gobierno del primer ministro Viktor Orbán sigue un rumbo ultranacionalista. También en la mayoría de los otros Estados miembros de la UE, las fuerzas políticas de derecha ganan cada vez más adherentes. Además, una creciente sensación de hastío político puede llevar a muchos ciudadanos europeos a abandonar el proyecto europeo de unificación, el cual efectivamente podría fracasar por una falta generalizada de confianza y lealtad.

Esta enumeración de las crisis internas y externas de la UE pone en evidencia que la amenaza al proyecto europeo va mucho más allá de la crisis financiera. Como destaca José Antonio Sanahuja, son al menos cuatro las dimensiones del proyecto europeo que ponen en cuestión su racionalidad, legitimidad, relevancia y viabilidad (Sanahuja, 2012), a saber:

1. La UE como proyecto económico capaz de promover la estabilidad, el crecimiento, y la competitividad internacional; 
2. La UE como experiencia federal, es decir, como un modelo político singular de gobernanza democrática cosmopolita, construcción postnacional o "postwestfaliana", o experimento inédito de "gobernanza multinivel";

3. La "Europa social", es decir, la UE como mecanismo de solidaridad transnacional, a través de políticas de cohesión económica, social y territorial; y

4. Su papel como actor global y poder civil (soft power), a través de la Política Común de Seguridad y Defensa.

La múltiple crisis europea exhibe los resultados de un proceso de veinticinco años de globalización durante el cual la Unión Europea aparentemente no ha sido capaz de implementar medidas protectoras que consoliden su modelo de integración social, política y económica. La crisis está cuestionando las bases y los valores que le dieron origen, al tiempo que exacerba las contradicciones entre los intereses nacionales y europeos. La supuesta unificación fiscal hasta ahora acordada, es decir, la constitucionalización del equilibrio presupuestal, es percibida por sus críticos como una imposición del modelo alemán al conjunto de Europa. También son notorios los rechazos a: 1) la implementación de políticas de gasto público comunitarias, expansivas en los países económicamente sólidos, para reactivar las economías en recesión; 2) la postergada unificación bancaria; 3) la creación de un fondo de garantía europeo; y 4) la creación de alguna suerte de eurobonos (Farfán Mendoza, 2014, p. 183).

A este déficit se agrega, en el ámbito político, una crisis de legitimidad evidente en el hecho de que muchos partidos políticos enfrentan una seria crisis de representación. La distancia creciente entre las instituciones democráticas, los actores políticos que actúan en su nombre y los ciudadanos es un hecho, tanto a nivel del conjunto de la UE como de cada uno de los países miembros, y ha determinado el auge de nuevos partidos y movimientos de protesta y articulación 
política, a veces con mensajes problemáticos, como la organización Europeos Patrióticos Contrarios a la Islamización de Occidente (Pegida, por sus siglas en alemán), en Alemania, así como de propuestas claramente antieuropeas, o por lo menos anti-Bruselas. Entre las características de estos nuevos actores colectivos se halla el rechazo a la democracia liberal representativa en favor de prácticas de democracia directa, así como el reclamo de una figura conductora fuerte.

Estas nuevas articulaciones políticas trascienden la disyuntiva derecha/ izquierda y reclutan sus adherentes tanto en la clase media como en la media-baja y baja. Sus adherentes prefieren un discurso populista y nacionalista y están en su vertiente de derecha contaminados de xenofobia, odio racial y antisemitismo. Los destinatarios de su rechazo son los inmigrantes, los refugiados y otras minorías, pero también la clase dirigente, el aparato burocrático en Bruselas y "los de arriba", quienes, según su crítica, se habrían alejado de los ciudadanos y sus preocupaciones cotidianas.

En muchos países, el centro del espectro político se debilita crecientemente. La tentación de lo autoritario, de la "illiberal democracy", gana cada vez más adherentes, como evidencian los casos de Trump en EE.UU., Marine Le Pen en Francia, Kaczyríski en Polonia, Geert Wilders en Holanda, el partido SVP de Blocher en Suiza, Strache y su partido FPO en Austria, el Dansk Folkeparti en Dinamarca, el Vlaams Belang en Bélgica, los Demócratas de Suecia y el UKIP en Gran Bretaña. En la mayoría de los casos se trata, como destacó recientemente Jean Pisani-Ferry, de la Hertie School of Governance en Berlín (Pisani-Ferry, 2016), de una nueva combinación de nacionalismo, pensamiento autoritario e intervención estatal, una mezcla de la cual quizá los únicos ejemplos sean el peronismo en Argentina y el putinismo en Rusia. El debate sobre el surgimiento de esa nueva ideología está en plena marcha. Debido a que 
aparentemente no existe un culpable y ni siquiera un chivo expiatorio, los ciudadanos inculpan a los políticos.

La causa del malestar ciudadano no es, sin embargo, solamente la crisis financiera y sus consecuencias. El malestar, como enseñan los ejemplos de Polonia y de EE.UU., tampoco es una mera reacción mecánica a la recesión. Téngase en cuenta que Polonia ha vivido en los años recientes un verdadero boom económico; Donald Trump, por su parte, tiene éxito en los Estados Unidos pese a que los niveles de desocupación en ese país son hoy inferiores a los de las décadas 70 a 90 del siglo pasado. Una causa más profunda del auge del populismo es, más bien, la mala situación de la clase media-baja en la mayoría de los países industrializados, una consecuencia del avance tecnológico y de la globalización que, conjugados, determinaron la desaparición de los puestos de trabajo y de los ingresos de aquellos obreros y empleados que realizaban trabajos monótonos. Ejemplos elocuentes de ello son Estados Unidos y Francia.

Siguiendo otra vez a Pisani-Ferry, existe el peligro de que la polarización del mercado laboral a consecuencia de la revolución digital aumente todavía más la franja de los populistas (Pisani-Ferry, 2016). Las ideas que los nuevos partidos manejan no son, en modo alguno, monopolio de la derecha. Por el contrario, se hallan también en la izquierda. Chantal Mouffe, filósofa belga y quizás la voz más influyente de la izquierda radical en Europa, escribe, por ejemplo, que en una "situación populista" sería necesario "marcar una frontera clara" entre "las elites del establishment " ("la casta") y "el pueblo" (Mouffe, 2015). Recurriendo a Carl Schmitt, Mouffe recomienda la confrontación radical, y aboga por un populismo de izquierda con el objetivo de crear "un pueblo", un "nosotros" homogéneo: de este lado está el verdadero y buen pueblo; del otro, las malas élites que lo explotan. 
Voces comparables han surgido también en América Latina. La misma mentalidad se manifiesta cuando la izquierda radical en Argentina denunció la victoria electoral de Macri como un "neogolpe" de la derecha, en elecciones que según todos los observadores han sido competitivas y limpias (Álvez, 2016), o cuando los chavistas condenaron la victoria electoral de la oposición en las elecciones parlamentarias venezolanas de diciembre de 2015 como expresión de un "golpe electoral" o una "crisis contrarrevolucionaria" (Infolatam, 2015).

Esa mentalidad supone la idea de una voluntad homogénea del pueblo y rechaza las normas y reglas de juego de la democracia representativa y el pluralismo, elemento esencial de la cultura democrática de Occidente. Lo trágico es que si una parte de la izquierda se sube a este tren, estará colaborando involuntariamente con la derecha. Actualmente se encuentran claros ejemplos de este tipo de discurso polarizante y de pensamiento populista de izquierda tanto en Europa (Syriza, en Grecia; Podemos, en España) como en América Latina (el chavismo en Venezuela, Cristina Kirchner en Argentina). La porosidad de las fronteras entre la derecha y la izquierda es notoria, por ejemplo, en las extrañas coaliciones entre el partido de Putin y diversos partidos o movimientos de derecha en la UE.

Como consecuencia de la acumulación de fenómenos de crisis se observa actualmente en Europa una política de ensimismamiento, una mirada adentro, acompañada de un auge de los nacionalismos (por ejemplo, en Hungría, Polonia y Eslovaquia). Un ejemplo más reciente es la reacción de algunos Gobiernos europeos a los últimos movimientos inmigratorios. Cada país miembro de la UE está reaccionando a la actual corriente inmigratoria según sus propios intereses. Algunos Gobiernos rechazan cualquier responsabilidad en el tema y cierran sus fronteras, como es el caso de Hungría y de otros países de Europa oriental, y más recientemente

\section{6}


también de Dinamarca y Suecia, que durante décadas fueron símbolos de libertad y Estados de bienestar. Otros países miembros de la Unión permiten que los migrantes y los refugiados pasen por su territorio (Croacia, Grecia), mientras una minoría decreciente (en la que se cuenta Alemania) los recibe de brazos abiertos, al menos hasta ahora. Esta situación socava el Acuerdo de Schengen, uno de los mayores éxitos del proyecto europeo, y arroja desastrosos efectos económicos, políticos y simbólicos para el proceso de integración.

Al problema migratorio se agregan conflictos bélicos regionales en el entorno de Europa: en el Oriente medio (Siria e Irak) y en Ucrania. Estos conflictos se hallan muy lejos de una solución pacífica y amenazan con expandirse hacia la propia UE. El manejo de estos conflictos consume muchos esfuerzos políticos y financieros y deja poco margen de acción y capacidades para una política exterior proactiva dirigida a otras regiones del mundo, como América Latina, una región comparativamente estable, pacífica y económicamente parte de la "clase media" en la estratificación mundial de desarrollo (y por lo tanto mayormente no receptora de ayuda oficial al desarrollo). La cacofonía de voces y estrategias europeas que se presentan para manejar la crisis financiera y las migraciones y la falta de una identidad europea en la población y de una narrativa convincente con respecto a la dirección futura del proyecto europeo han llevado a algunos analistas a hablar ya del fin de la UE tal como la conocemos, es decir, el fin del concepto según el cual la integración europea sería un proceso gradual progresivo (Simms y Zeeb, 2015).

Para hacer frente a la acumulación de fenómenos de crisis aquí mencionados, son necesarias respuestas fuertes, tanto por parte de Bruselas como de los Gobiernos de los países miembros. Las respuestas hasta hoy ofrecidas son, sin embargo, insuficientes. Las más importantes y urgen- 
tes deberían atender el perfeccionamiento de un modelo económico sostenible, la consolidación solidaria de la zona euro, la creación de un verdadero sistema de refugiados y de asilo, una efectiva protección de las fronteras exteriores de la UE (condición indispensable para mantener el espacio Schengen), la profundización de la democracia en el sistema político europeo, y el fortalecimiento de la política exterior europea a través de la política común de seguridad y defensa de la UE.

Del panorama recién esbozado de la UE, es factible delinear tres posibles escenarios:

1. La paulatina renacionalización;

2. La conversión de la moneda única, el euro, en un mecanismo disciplinario de los mercados financieros, fracturando el binomio disciplina-solidaridad que históricamente caracterizaba al proyecto europeo;

3. La redefinición de la UE como proyecto de gobernanza efectiva de la globalización, garantizando la cohesión y la solidaridad intraeuropeas; es decir: no "más Europa", sino "mejor Europa".

El desarrollo europeo reciente permite atisbar numerosas evidencias de los escenarios 1) y 2), en su conjunto señales de una creciente erosión de la integración europea y una demostración de poder de los Estados nacionales. Lamentablemente, el escenario 3) es el menos probable. Sin una protección de las fronteras exteriores del espacio Schengen y sin una cooperación que paralelamente garantice el derecho de asilo, no se puede mantener la Europa de Schengen, la del libre tránsito de ciudadanos libres (Von Lucke, 2015, p. 45). Una política de aislamiento (la fortaleza Europa) no puede ser la solución. 


\section{Enseñanzas mutuas}

Se reconocen algunas señales positivas en las relaciones recientes entre Europa y América Latina. En tal sentido, resultó sintomática la primera cumbre entre la UE y la CELAC, celebrada en Santiago de Chile en enero de 2013. El encuentro marcó el inicio de una nueva etapa en las relaciones eurolatinoamericanas, caracterizada por un visible reequilibrio de dichas relaciones, capaz de atenuar en parte las asimetrías tradicionales. La UE tiene en la CELAC por primera vez una contraparte única. Esa es, al menos, la esperanza, y sólo el futuro dirá si la misma se justifica, pues lo cierto es que con o sin la CELAC América Latina sigue siendo una región particularmente fragmentada, como dejaron en evidencia las cuatro cumbres de la CELAC celebradas hasta el momento.

Un segundo elemento positivo que ha ayudado a generar relaciones birregionales más simétricas y equilibradas que en el pasado es el hecho de que, como subrayan Susanne Gratius y José Antonio Sanahuja, los consejos vienen hoy, más bien, del otro lado del Atlántico, dirigidos al viejo continente y ya no, como antes, en el sentido opuesto (Gratius y Sanahuja, 2013). Esto se relaciona con al menos tres fenómenos: 1) el declive de la UE como actor normativo y modelo; 2) el auge económico de América Latina y su actuación más autónoma y diversificada en el ámbito internacional; y 3) la mayor orientación de ambas regiones hacia Asia.

Como consecuencia de los fenómenos de crisis antes mencionados, la UE deja de ser vista hoy como fuente de soluciones, y pasa a ser origen y causa de problemas. La región parece entrar en una "década perdida" en términos económicos, políticos y sociales. Al respecto, la entonces presidenta de Brasil, Dilma Rousseff, habló en ese contexto de un falso dilema entre austeridad y crecimiento (Mars y Cué, 2012). Europa puede, por otro lado, también aprovechar 
la crisis como una oportunidad histórica, en el sentido de promover un reordenamiento de los mercados financieros globales y de las instituciones de la gobernanza global. Para ello, la UE podría encontrar socios en América Latina.

Sin embargo, lo que se ve hoy no es una respuesta europea común a los diferentes cambios intra- e interregionales, sino más bien respuestas por parte de los Gobiernos nacionales, carentes de coordinación y perjudiciales al proceso de integración, lo que llevó a Mario Draghi, presidente del Banco Central Europeo (BCE), a decir que el modelo social europeo es cosa del pasado (The Wall Street Journal, 2012). Tanto la insistencia en una política de austeridad, como proclaman Alemania y algunos países nórdicos, como las respuestas no-coordinadas al fenómeno de las recientes olas inmigratorias, apuntan en esa dirección.

¿Cuáles son, entonces, las enseñanzas para ambas partes?

1. La austeridad por sí misma no resuelve el problema de la deuda, menos aún en tiempos de recesión (George, 2013). Una austeridad sin incentivos, como la ensayada en Grecia, España y Portugal, sólo prolonga la crisis y apareja enormes costos sociales. Europa y América Latina pueden aprender sin duda de la falacia de la denominada "austeridad expansiva". Los ajustes adoptados por los Gobiernos latinoamericanos en los años 80 fueron procíclicos, tuvieron un fuerte costo social y provocaron un ciclo recesivo. Paradójicamente, hoy es el propio FMI quien alerta, conjuntamente con los líderes latinoamericanos, sobre los riesgos de subestimar el efecto multiplicador fiscal de la austeridad. Sin embargo, como Farfán Mendoza (2014) ha subrayado con razón, la experiencia latinoamericana desde 2002 hasta 2012 parece estar dándole la razón a la postura alemana, porque América Latina supo sobreponerse sin grandes sobresaltos a la crisis financiera global a partir de 2008 gracias a la aplicación de elementos de la política econó- 
mica de Alemania: equilibrio presupuestal (particularmente a través del superávit primario), competitividad salarial, avance en reformas estructurales y preferencia para las exportaciones. Algunos países, sobre todo en el sur de la región (Brasil, Uruguay y otros) impulsaron durante la década dorada (2003-2013) una política de incrementos salariales muy importantes, políticas de impulso al mercado interno y a nuevas políticas sociales (Boyer, 2014). A diferencia de los países de la zona euro, imposibilitados para devaluar su moneda común, los latinoamericanos sí disponen de este instrumento, aunque en años de "vacas flacas" deben ajustar su política cambiaria a las necesidades de la reactivación económica (Farfán Mendoza, 2014, pp. 188 y ss.).

2. Una medida anticrisis adicional es aprovechar un buen desempeño económico para avanzar en la agenda social, como hicieron los Gobiernos progresistas en el cono sur entre 2003 y 2012 .

3. El efecto dañino de los diagnósticos equivocados. La crisis de la deuda fue inicialmente considerada por parte del G7, de los organismos financieros internacionales y de una mayoría de los economistas no como una crisis de solvencia, sino una mera crisis de liquidez que la pronta recuperación del crecimiento resolvería por sí sola a través de un ajuste. Debieron pasar seis o siete años para que se reconociera la necesidad de una "quita de deuda", por ejemplo, según el modelo del Plan Brady. Se nacionalizó la deuda en beneficio de acreedores y accionistas, y a costa de la Hacienda pública. El marco fiscal tal como lo prevé el Acuerdo de Maastricht en realidad nunca ha funcionado. Tampoco se ha creído en un rescate financiero, o "bailout ". Además, los economistas y autores del Acuerdo de Maastricht tampoco previeron las grandes resistencias. El problema central fue, sin embargo, de tipo estructural. La economista suiza Beatrice Weder di 
Mauro, profesora de la Universidad de Maguncia y uno de los "cinco sabios de Economía" de Alemania, explica que en realidad se trata de tres déficits, o mejor dicho, de tres noes contenidos en el Tratado de Maastricht: 1) un no con respecto a una opción "exit" para abandonar la Unión; 2) un no a la posibilidad de recibir un "ancla de rescate" por parte de la Unión; y finalmente 3) un no a un arreglo para el caso de insolvencia estatal. De los tres no, fue el número 3) el que resultó excesivo, por el simple hecho de que nadie pensaba que ni un Estado europeo ni un banco "de peso" podrían declarar alguna vez la insolvencia (Weder di Mauro, 2011). Después del crack de 2008, la mayoría de los expertos tampoco advirtió la necesidad de un arreglo al respecto, y numerosos Gobiernos europeos se resistieron a un arreglo de esas características porque no querían perder parte de sus competencias. Por lo tanto, un aporte importante para finalizar con la crisis es buscar un acuerdo o una reestructuración exitosa de la deuda con los acreedores siguiendo, por ejemplo, el Plan Brady, por el cual algunos Gobiernos latinoamericanos pagaron en su momento USD 0.35 por cada dólar adeudado. También el caso de la reestructuración de la deuda argentina se presta para extraer lecciones (George, 2013).

4. Como destaca una corriente reciente de literatura económica sobre inestabilidad y crisis financiera, el modelo europeo de cooperación monetaria y financiera no es transferible a regiones del Sur, como América Latina y el Caribe. Estas regiones deberían, más bien, adoptar diferentes mecanismos de cooperación y coordinación monetario-financiera, dado que su prioridad, a diferencia de la de los países del Norte, no es el incremento de la eficiencia alocativa, sino la creación de condiciones para resistir los shocks globales externos, proporcionar liquidez a corto plazo y establecer crecientes nexos

\section{2}


comerciales y financieros que amortigüen los shocks externos (Krampf y Fritz, 2015).

5. Las reglas claras en política fiscal son imprescindibles. Estas reglas, concebidas como "el conjunto de normas que permiten regular el proceso de elaboración, aprobación, ejecución y supervisión de los programas presupuestales de los Gobiernos" (Galán Figueroa, 2014, p. 121), deben fijar ciertas restricciones sobre el déficit y la deuda pública y vedar la financiación del gasto corriente a través de la deuda (con cuyo pago cargan las generaciones venideras). Para que en situaciones de crisis externa las autoridades "puedan contar con este margen de maniobra, la regla de política que se esté utilizando debe ser sencilla y flexible y debe garantizar el crecimiento económico sin distorsionar la relación entre las empresas e individuos y, sobre todo, que no permita relajar la disciplina fiscal" (Galán Figueroa, 2014, pp. 122 y ss.).

6. Tanto en Europa como en América Latina se observa en tiempos recientes un aumento del populismo en movimientos y partidos de protesta, en su mayoría de derecha, pero también de izquierda, resultado de la crisis financiera y sus graves impactos económicos, como la erosión de la clase media baja. Este tipo de oposición política se percibe a sí misma como la defensora de un pueblo necesitado de protección contra "aquellos de arriba", es decir, el capital especulativo y una élite de poder capitalista, muchas veces corrupta, que se ha desacoplado de los deseos e intereses reales de la población. Estas nuevas fuerzas políticas coinciden, trascendiendo la diferenciación derecha-izquierda, en una emotiva postura antisistema, su antipluralismo, su antiparlamentarismo, y, a veces, en sus tendencias xenófobas y racistas. Sus propuestas son una reacción a la creciente falta de credibilidad de la política mainstream y suelen 
estar muy lejos de ser un programa coherente; apuntan principalmente a medidas de política económica: expulsión de emigrantes, cierre de fronteras, regreso a la independencia de los bancos centrales y fuertes intervenciones del Estado en la economía.

7. Europa necesita una nueva narrativa y debe ser más receptiva a las recomendaciones provenientes de América Latina y a sus ofertas de cooperación. Ello incluye también la necesidad de "latinoamericanizar" las cumbres birregionales, lo que requiere también un mayor compromiso político y financiero de la parte latinoamericana y una política nacional y regional más articulada de esa región hacia la UE. Con la creación de la CELAC, Europa y América Latina tienen por primera vez la oportunidad de iniciar un diálogo más horizontal y entre verdaderos socios. Sin embargo, se cita, por resultar oportuna también aquí, una pregunta formulada hace ya muchos años por Henry Kissinger: “¿qué número de teléfono debo seleccionar para hablar con Bruselas?”. Debemos constatar que, si bien América Latina y el Caribe se presentan, desde la primera cumbre birregional de la CELAC en 2013 en Santiago de Chile, como un socio coherente, en realidad la entidad sigue teniendo, como formulara recientemente Joaquín Roy, muchos números de teléfono (Roy, 2013).

8. En breve: las lecciones y los aprendizajes son mutuos (y no de un solo lado, como Gratius y Sanahuja -2013suponen). La experiencia latinoamericana de los años 1980 y 1990 refleja el sinsentido de la austeridad pura y dura, cuyos costos económicos, políticos y sociales son imprevisibles e incontrolables. Esta experiencia señala, asimismo, el limitado valor de extrapolar modelos, sea en Europa, sea en las relaciones birregionales. Por ejemplo, el modelo alemán de crecimiento basado en exportaciones (y no de consumo) no puede

\section{4}


ser la receta mágica para otros países europeos. En términos políticos, dejar atrás las "décadas perdidas" conllevó para América Latina un mayor distanciamiento de Washington y de su capitalismo a ultranza. Los países latinoamericanos exitosos (sobre todo Brasil y Uruguay, y con limitaciones Chile, Perú y Colombia) aplicaron políticas económicas diferentes, más cercanas al capitalismo renano. Históricamente, las principales enseñanzas de la Unión Europea para América Latina han sido la integración, la solidaridad, el Estado democrático de derecho y la justicia social. Estos valores no han perdido su importancia, a pesar del hecho de que se encuentran hoy a la defensiva frente a los impactos de la crisis financiera y de una Europa en crisis múltiples. Sin embargo, no parece posible reanimar en la práctica dichos valores sin contar con una nueva narrativa que dé al proyecto europeo un rumbo claro, así como tampoco se considera factible sin un nuevo intento europeo de conciliar austeridad y competitividad con solidaridad, e inclusión social con legitimidad democrática, valores estos consagrados en los tratados fundacionales de la UE. Lamentablemente, lo que se ve en Europa actualmente va en el sentido contrario, como lo muestra, por ejemplo, el auge, desde las últimas elecciones para el Parlamento Europeo, de un crudo populismo de derecha en la mayoría de los veintisiete países miembros de la UE.

Álvez,A. (I4 de enero de 2016). "Neogolpismo decided to Bibliografía impose conservative order”. Latin American Press. Recuperado de:http://www.lapress.org/ar ticles.asp?art=7255 Bensusán, G. (coord.) (2006). Disenio legal y desempeño real: instituciones laborales en América Latina. México: UNSAM, Miguel Ángel Porrúa. 
Bizberg, I. (coord.) (20I4). Variedades de capitalismo en América Latina: los casos de México, Brasil, Argentina y Chile. México: El Colegio de México.

Boyer, R. (20 I4)."Is More Equality possible in Latin America? A Challenge in a World of Contrasted but Interdependent Inequality Regimes". DesiguALdades.net, Working Paper Series, (67), 94.

CEPAL (2009a). Balance preliminar para América Latina y el Caribe. Santiago de Chile: CEPAL. (2009b). "La reacción de los gobiernos de las Américas frente a la crisis internacional: una presentación sintética de las medidas de políticas anunciadas hasta el 3 I de marzo de 2009" (informe presentado en la Quinta Cumbre de las Américas, Puerto España). Recuperado de: www.cepal.org/publicaciones/xml/8/35768/2009192-LareacciondelosgobiernosdelasAmericas-pos3 I marzo2009

—_ y OIT (comps.) (2009). Coyuntura laboral en América Latina y el Caribe: crisis y mercado de trabajo. Santiago de Chile: CEPAL, OIT.

Eidelmann, V. (I8 de marzo de 20I0).“Twoo cheeres for Latin America". International Economic Bulletin. Recuperado de: http://www.carengieendowment.org/2010/03//8/twoocheers-for-latin-america

Farfán Mendoza, G. (20I4). "La crisis europea: lecciones para las políticas económicas de América Latina”, en R. M. Piñón Antillón (coord.), La crisis de la zona euro y América Latina. Lecciones del pasado y del presente (pp. I5I-193). México: UNAM.

Ferrer, A. (1984). Poner la casa en orden. Buenos Aires: El Cid Editores.

FMI (20I2). Perspectivas de la economía mundial. Reanudación del crecimiento, peligros persisentes. Washington: FMI. 
Foxley, A. (2009). Recovery: The Global Financial Crisis and Bibliografía Middle-Income Countries. Washington: Carnegie Endowment for International Peace.

Galán Figueroa,J.(20I4).“'La gobernanza de las reglas fiscales versus la discrecionalidad del gasto público", en R. M. Piñón Antillón (coord.), La crisis de la zona euro y América Latina. Lecciones del pasado y del presente (pp. 109-129). México: UNAM.

George, S. (20I3). Surviving a debt crisis: Five lessons for Europe from Latin America. Nueva York: Bertelsmann Foundation.

Gratius, S., y Sanahuaja, J. A. (20I3). "Enseñanzas latinoamericanas a la crisis del euro". Política Exterior, (enero/ febrero), I44-I54.

Infolatam (03 de octubre de 20I4). "América Latina encara años de crecimiento bajo, coinciden el BID, BM y FMI “. Recuperado de: http://www.infolatam.com/20I4/I0/03/ america-latina-encara-anos-de-crecimiento-bajo-coinciden-el-bid-bm-fmi/

(20 de diciembre de 20I5). "Esta es la triple estrategia de Maduro para licuar la victoria opositora". Recuperado de: http://www.infolatam.com/20I5/I2/2 I/ esta-es-la-triple-estrategia-de-maduro-para-licuar-lavictoria-opositora

Krampf, A., y Fritz, B. (20I5). "Coping with financial crisis: explaining variety in regional arrangements", en B. Fritz, yA. Krampf (eds.), Coping with Crisis:Variations of Financial Crisis Management at the Regional Level, Special Issue of Contemporary Politics, 2 I (2), I 27 - I 44.

La Jornada (I8 de abril de 20I3). “Aconseja a la UE acabar con las medidas de austeridad”, p. 29.

Langhammer, R. J. (2009). Wie kónnte die Krise auf die Wirtschaftsentwicklung der BTI-Ldnder einwirken und den BTI verdndern? Einige Thesen. Gütersloh: Mimeo, Bertelsmann-Stifrung. 
Mai, C. (05 de marzo de 2009). “Lateinamerika kann Krise nicht entwischen”. Financial Times Deutschland. Recuperado de: http://www.ftd.de/politik/international/ Ansteckung-Lateinamerika-kann-krise-nicht-entwischen Mars, A., y Cué, C.E. (I8 de noviembre de 20I2)."Rousseff advierte de que "la austeridad exagerada se derrota a sí misma"”.'Recuperado de:http:// economia/2012/1 I/I9/ actualidad/I $3533 \ldots$

Mouffe, C. (30 de marzo de 20I5). Für einen linken Populismus. Recuperado de: www.ipg-journal.de

Núñez, R. (20II). “América Latina apuesta de nuevo por las medidas aniticíclicas". Infolatam. Recuperado de: http://www.infolatam.com/20I I/I2/06/america-latinaapuesta-de-nuevo

- (13 de mayo de 20I2a). "América Latina prefiere la reactivación (Francoise Hollande) a la austeridad (Angela Merkel)". Infolatam. Recuperado de: http://www. infolatam.com/20 I 2/05/I3/america-latina-prefiere-lareactivaciónfrancois

- (28 de mayo de 20l2b). "América Latina ante el agravimiento de la crisis de la EU”. Infolatam. Recuperado de: http://www.infolatam.com/2012/05/28/Americalatina-ante-el-agravamiento

Oppenheimer, A. (2010). ¡Basta de historias! La obsesión latinoamericana con el pasado y las 12 claves del futuro. Buenos Aires: Editorial Sudamericana.

Piñón Antillón, R. M. (2014). “La Unión Europea y América Latina ante la crisis económica: crecimiento, desarrollo y fundamentales”, en R. M. Piñón Antillón (coord.), La crisis de la zona euro y América Latina. Lecciones del pasado y del presente (Pp. 47-82). México: UNAM.

Pisani-Ferry, J. (02 de febrero de 2016). "Wurzeln des Populismus. Die Erosion der unteren Mittelschicht hat die Glaubwürdigkeit der etablierten Politik ruiniert". Süddeutsche Zeitung, p. 3. 
Roy, J. (II de enero de 20I3). "Los teléfonos de Europa y América Latina”. El País. Recuperado de: http://blogs. elpais.com/atalantis/2013/0I/los-telefonos-de-europa-y..

Sanahuja,J. A. (20I2). “Las cuatro crisis de la Unión Europea”. Anuario CEI-PAZ, (5), 5 I-84.

Sangmeister, H. (2010). “Lateinamerikas Wirtschafr 2010 auf Erholungskur”. GIGA Focus Lateinamerika, (I), 8.

Simms, B., y Zeeb, B. (05 de septiembre de 2015). "Heiliges Romisches Reich ii”. Süddeutsche Zeitung, p. 5.

Steinberg, F. (I 2 de septiembre de 20 I3).“El fin de la fiesta de los emergentes, especialmente peligroso para América Latina”. Infolatam. Recuperado de: http://www.infolatam. $\mathrm{com} / . . . . /$ el-fin-de-la-fiesta-de-los-emergentes-espc.

The Wall Street Journal (23 de febrero de 20I2). "Q\&A: ECB President Mario Draghi”. Recuperado de: http://blogs. wsj.com/eurocricic/20 I /02/23/qa-ecb-presidentmario-draghi/).

Von Lucke. A. (20I5). "EU in Auflosung? Die Rückkehr der Grenzen und die populistische Gefahr". Bldtter für deutsche und internationale Politik, (I0), 45-54.

Weder di Mauro, B. (I8 de septiembre de 20I I). "Wie die Eurokrise gemeistert wird”. NZZ-TV, Standpunkte. 